\title{
High levels of soluble herpes virus entry mediator in sera of patients with allergic and autoimmune diseases
}

Hyo Won Jung', Su Jin La', Ji Young Kim² Suk Kyeung Heo', Ju Yang Kim ${ }^{1}$, Sa Wang ${ }^{3}$ Kack Kyun Kim, Ki Man Lee, Hong Rae $\mathrm{Cho}^{6}$ Hyeon Woo Lee', Byungsuk Kwon' Byung Sam Kim ${ }^{1}$ and Byoung Se Kwon ${ }^{1,7,8}$

${ }^{1}$ The Immunomodulation Research Center and

Department of Biological Sciences

University of Ulsan, Ulsan $680-749$, Korea

${ }^{2}$ The Immunomics Inc.

Ulsan 680-749, Korea

${ }^{3}$ Department of Microbiology and Immunology

Indiana University School of Medicine

Indianapol's, IN 46202, USA

${ }^{4}$ Department of Oral Microbiology

College of Dentistry, Seoul National University

Seoul 110-744, Korea

${ }^{5}$ Department of Internal Medicine

Ulsan University Hospital, University of Ulsan

Ulsan 682-714, Korea

${ }^{8}$ Department of Surgery

Ulsan University Hospital, University of Ulsan

Ulsan 682-714, Korea

${ }^{7}$ LSU Eye Center

Louisiana State University School of Medicine

2020 Gravier Street New Orleans LA 70112, USA

${ }^{8}$ Corresponding author: Tel, 82-52-259-2392;

Fax, 82-52-259-2740; E-mail, bskwon@mail.ulsan.ac.kr

Accepted 23 October 2003

Abbreviations: DC, dendritic cell; HVEM, herpes virus entry mediator; GST, glutathione S-transferase; MLR, mixed leukocyte reaction; RA, theumatoid arthrifs; SHVEM, soluble HVEM; SLE, systemic lupus exythematosus; TNFR, TNF receptor; TRAF, TNFR associated factor

\footnotetext{
Abstract

Herpes virus entry mediator (HVEM) is a newly discovered member of the tumor necrosis factor receptor (TNFR) superfamily that has a role in herpes simplex virus entry, in $T$ cell activation and in tumor immunity. We generated mAb against HVEM and detected soluble HVEM (SHVEM) in the sera of patients with various autoimmune diseases. HVEM was constitutively expressed on $\mathrm{CD4}^{+}$and $\mathrm{CD8}^{+} \mathrm{T}$ cells, CD19 ${ }^{+} \mathrm{B}$ cells, CD14 ${ }^{+}$monocytes,
}

neutrophils and dendritic cells. In three-way MLR, $\mathrm{mAb} 122$ and 139 were agonists and $\mathrm{mAb} 108 \mathrm{had}$ blocking activity. An ELISA was developed to detect sHVEM in patient sera. SHVEM levels were elevated in sera of patients with allergic asthma, atopic dermatitis and rheumatoid arthritis. The mAbs discussed here may be useful for studies of the role of HVEM in immune responses. Detection of soluble HVEM might have diagnostic and prognostic value in certain immunological disorders.

Keywords: asthma; atopic; autoimmune diseases; dermatitis; inflammation mediators; rheumatoid arthritis; tumor necrosis factor

\section{Introduction}

Members of the tumor necrosis factor receptor (TNFR) superfamily share a similar architecture of their extracellular domain; this consists of a series of cysteine-rich segments containing 30-40 amino acids with six cysteines in each segment (Mallett et al., 1991). They are involved in the regulation of diverse immune functions. Some of the members of this family regulate signals leading to apoptosis, whereas others are involved in lymphocyte activation and differentiation (Locksley et al., 2001; Kwon et al., 2003). The open reading frame of herpes virus entry mediator (HVEM) encodes a 283 amino acid sequence, two perfect TNFR-like cysteine-rich domains, two imperfect cysteine-rich domains, and a short cytoplasmic tail similar to that seen in 4-1BB and CD40 (Montgomery et al., 1996; Kwon et al., 1997). Because an HVEM-Fc fusion protein inhibited proliferation in a mixed lymphocyte reaction using patient lymphocytes (Harrop et al., 1998), HVEM may either play a direct role in $T$ cell stimulation or bind to a ligand that stimulates $T$ cell proliferation. HVEM is a cellular mediator of the entry of herpes simplex virus type-1 (HSV-1) (Montgomery et al., 1996) and interacts directly with the HSV virion glycoprotein D $(g D)$ required for entry into HVEM expressing cells (Whitbeck et al., 1997). Hsu et al. (1997) found that the cytoplasmic region of HVEM binds to several members of the TNFR-associated factor (TRAF) family, namely, TRAF1, TRAF2, TRAF3, and TRAF5, but not to TNFR4 or TRAF6, and that it activates transcription factors NF- $\mathrm{kB}$ and AP-1 (Marsters et al., 1997). As anti-HVEM mAb are needed for or in-depth studies 
of the role of HVEM in immune responses and in clinical settings, we generated several mAbs and used them to characterize HVEM, and to detect soluble HVEM in clinical samples.

\section{Materials and Methods}

Cells and cell culture

Monocyte-like cell lines HL-60, U937, and THP-1, human $\mathrm{CD4}^{*} \mathrm{~T}$ cell lines Jurkat and $\mathrm{PM}-1$, human embryonic kidney cell line 293, and SP2/0 myeloma cell line were obtained from the American Type Culture Collection (ATCC, Manassas, VA). They were cultured in either RPMI 1640 or DMEM, supplemented with $10 \%$ FBS (Hyclone) and antibiotics. Growth was at $37^{\circ} \mathrm{C}$ with $5 \% \quad \mathrm{CO}_{2} /$ air.

\section{Expression and purification of recombinant HVEM-GST and HVEM-Fc fusion proteins}

We used PCR to amplify the cDNA sequence that encodes the ectodomain of HVEM. It was fused in frame with the GST-binding domain of glutathionine S-transferase (GST) or with human $\mathrm{IgG}_{1} \mathrm{Fc}_{\mathrm{c}}$ (including hinge, $\mathrm{CH}_{2}$ and $\mathrm{CH}_{3}$ domains). Each of the in-frame fusions was confirmed by sequencing before being cloned into the PGEX-3 or pcDNA3 expression vector. pGEX-3-HVEM-transformed Escherichia coli were grown to an optical density of 0.6 ( A $_{590}$ ) before protein expression was induced by the addition of $2 \mathrm{mM}$ (final concentration) isopropyl thiogalactopyranoside (IPTG). The HVEM-GST fusion protein was purified by twostep chromatography with GSH-sepharose 4B. HVEMFc fusion protein was produced in NIH 3 T 3 cells and purified with a protein $G$ column. An automatic peptide sequencer ( $\mathrm{ABI}$, Perkin-Elmer, Norwalk) was used to determine $\mathrm{N}$-terminal amino acid sequences.

\section{Immunization and fusion}

A 6-8 week-old female Balb/c mouse (Harlan, Indianapolis, IN) was injected i.p. with $30 \mu \mathrm{g}$ HVEM-GST fusion protein emulsified with an equal volume of Freund's complete adjuvant (Gibco-BRL, Gaithersburg, MD). After two weeks the mouse was injected IP with the same amount of HVEM-GST fusion protein emulsified with an equal volume of Freund's incomplete adjuvant. Two weeks later the mice received a third injection i.v. of $30 \mu \mathrm{g}$ of HVEM-GST in PBS. Fusion of myeloma cells with splenocytes was performed as described by Kohler and Milstein (1975). SP2/0 were used as fusion partner during exponential growth, with more than $95 \%$ viability. Primed lymphocytes were mixed with myeloma cells at a ratio of $5: 1$ and fused in $50 \%(w / v)$ polyethylene glycol MW 1500 (Boeh- ringer Mannheim, Indianapolis, IN). Cells were selected in HAT medium (Boehringer Manheim) using peritoneal macrophages as feeder cells. Antibody activity was determined after 10-14 days.

\section{ELISA screening}

We determined the anti-HVEM activity of supernatants of the hybridoma cells by ELISA (Jin et al., 2001). ninety-six-well polypropylene microplates (Falcon, Oxnard, CA) were coated with $5 \mathrm{mg} / \mathrm{ml}$ HVEM-Fc in $\mathrm{NaHCO}_{3}$ overnight at $4^{\circ} \mathrm{C}$, blocked with $3 \% \mathrm{BSA}$, and incubated with the supernatants. Goat anti-mouse IgG conjugated with horseradish peroxidase (Sigma, St. Louis, CA) was used as secondary antibody. Plates were washed five times with PBS/Tween-20 before detecting bound antibody by incubation with $A B T$ peroxidase substrate (Kirkegaard and Perry Lab, Inc., Gaithersburg, MD). Serum obtained from the mouse used to provide the splenocytes was used as a positive control. The $\mathrm{lg}$ class and subclass of the resulting monoclonal antibodies was determined with the ImmunoPure Monoclonal Antibody Isotyping Kit (Pierce, Rockford, IL).

\section{Purification of monoclonal antibodies}

Balb/c mice were primed with Pristane and injected IP with subcloned hybridoma cells to induce ascites formation. The mAbs were purified from the ascites fluid by affinity column chromatography with protein G-Sepharose (Zymed Lab, Inc, South San Francisco, CA) (Coligan et al., 1991). The three monoclonal antibodies (mAbs) used in this work, clones 108, 122 and 139, were of isotypes $\lg \mathrm{G} 1$ (colnes, 108 and 122) or lgG2a (clone 139).

\section{SDS-PAGE and Western blot analysis}

HVEM-GST was purified by two-step chromatography with GST-sepharose $4 \mathrm{~B}$, and used as control for Western blot analysis. Lysates $\left(5 \times 10^{7}\right.$ cells $\left./ \mathrm{ml}\right)$ of THP-1 and Jurkat cells were digested in lysis buffer [1\% Triton $\mathrm{X}-100$ in $150 \mathrm{mM} \mathrm{NaCl}$ and $20 \mathrm{mM}$ Tris- $\mathrm{HCl}(\mathrm{pH} 8.0)]$ at $4^{\circ} \mathrm{C}$ for $30 \mathrm{~min}$. The lysates and HVEM-GST were denatured by boiling for $5 \mathrm{~min}$ with $0.5 \%$ SDS and $1 \% \beta$-mercaptoethanol, subjected to SDS-PAGE, and transferred to nitrocellulose membranes. The membranes were blocked in reaction buffer (10 mM Tris [pH 7.4], $150 \mathrm{mM} \mathrm{NaCl}, 10 \%$ nonfat dried milk, $0.05 \%$ Tween-20) for $1 \mathrm{~h}$ and incubated with anti-HVEM mAb 108 diluted 1:5,000 in reaction buffer, followed by horse peroxidase-coupled goat anti-mouse lgG (Boehringer Mannheim) diluted $1: 10,000$. Secondary antibody was detected by incubation in ECL reagent (Amersham Biosciences, Piscataway, NJ) and exposure to X-ray film (Kodak, 
Rochester, NY).

\section{Flow cytometry}

293 cells transfected with HVEM-pcDNA3 were stained $48 \mathrm{~h}$ after transfection. Cultured cells were also stained with or without stimulation with anti-CD3 (OKT3; $1 \mu \mathrm{g} / \mathrm{ml})$ and LPS $(100 \mathrm{ng} / \mathrm{ml})$. They were washed twice, resuspended in $1 \%$ paraformaldehyde and analyzed by flow-cytometry with a FACScan (Becton Dickinson, San Jose, CA). Human PBMC were isolated from healthy donors by Ficoll-Paque Plus (Amersham Pharmacia, Oakville, Canada) at 300 $g$ for $30 \mathrm{~min}$. Neutrophils were isolated by polymorphprep (Nycomed Pharma AS, Oslo, Norway) gradient centrifugation according to the manufacturer's protocol. PBMC and neutrophils were washed in complete culture media. FITC-conjugated anti-HVEM $\mathrm{mAb} 122$, PE-conjugated anti-CD4, CD8, CD 19, and CD14 mAbs (BD PharMingen, San Diego, CA) were used to detect PBMC that expressed HVEM. Isotypematched antibodies were used as controls.

\section{Dendritic cell maturation}

Dendritic cells (DC) were prepared from monocytes of PBMC as previously described (Brown et al., 2003). To obtain monocytes, non-adherent cells were removed following $2 \mathrm{~h}$ incubation at $37^{\circ} \mathrm{C}$, and adherent cells scraped off culture dishes. The monocytes were further enriched by incubation with anti-CD14 magnetic beads (Miltenyi Biotec., Bergisch Gladbach, Germany). They were cultured in 6 -well plates at $2 \times$ $10^{6}$ cells/well with $\mathrm{GM}-\mathrm{CSF}(800 \mathrm{U} / \mathrm{ml})$ and $\mathrm{IL}-4$ $(1,000 \mathrm{U} / \mathrm{ml})$ for 6 days. Maturation of immature DCs (iDCs) was accomplished by transferring the cells to new 6-well plates and supplementating with monocyte- conditioned medium and TNF- $\alpha$ at final concentrations of $20 \% \mathrm{vol} / \mathrm{vol}$ and $10 \mathrm{ng} / \mathrm{ml}$, respectively. Fresh GM-CSF and IL-4 were present throughout growth. The mature DCs (mDCs) were consistently made up of $90-95 \%$ CD $11 c^{*}$ cells.

\section{MLR-mediated PBMC proliferation}

PBMC were isolated from three healthy adult volunteers by Ficoll gradient centrifugation at $400 \times g$ for $30 \mathrm{~min}$. They were recovered, washed in RPMI 1640 (Life Technologies, Gaithersburg, MD) supplemented with $10 \%$ fetal bovine serum and antibiotics, and adjusted to $1 \times 10^{6}$ cells $/ \mathrm{ml}$ in the case of two of the donors, and to $2 \times 10^{5}$ cells $/ \mathrm{ml}$ in the third. Fifty $\mu \mathrm{ll}$ of each cell suspension was added to a 96-well (round bottom) plate (Falcon, Franklin Lakes, NJ) together with 50 ul of mAb 108, 122, 139 or unrelated control mAb. The plates were incubated at $37^{\circ} \mathrm{C}$ in $5 \% \mathrm{CO}_{2}$ for $96 \mathrm{~h}$. One $\mu \mathrm{Ci}$ of $\left[{ }^{3} \mathrm{H}\right]$ methylthymidine
(ICN Biomedicals, Costa Mesa, CA) was then added for an additional $16 \mathrm{~h}$. The cells were harvested, and radioactivity counted.

\section{Detection of soluble HVEM (sHVEM) in human serum} sHVEM was detected by ELISA using 108 as capturing $\mathrm{mAb}$, and 122 as detecting $\mathrm{mAb}$. A standard curve was constructed with HVEM-Fc (R \& D system, Minneapolis, MN) as antigen. The ELISA plate was coated with $100 \mu \mathrm{g}$ per well of mAb $108(1 \mu \mathrm{g} / \mathrm{ml})$, and blocked with $200 \mu \mathrm{g} /$ well of $4 \%$ BSA. Samples of $100 \mu \mathrm{g} / \mathrm{well}$ were added, incubated at $37^{\circ} \mathrm{C}$ for 1 $\mathrm{h}$ and washed. Biotin-labeled mAb 122 was then added and incubation continued for another $1 \mathrm{~h}$ at $37^{\circ} \mathrm{C}$. The plate was washed and streptavidin-conjugated horse-radish peroxidase added. TMB substrate solution (Endogen, Pierce biotechnology, Rockford, $\mathrm{CA}$ ) was introduced and absorbance at $450 \mathrm{~nm}$ measured. The standard curve constructed with HVEM-Fc indicated that the sensitivity limit was $16 \mathrm{pg} / \mathrm{ml}$. All assays were performed blind, and at the same time, on coded sterile samples.

\section{Serum SHVEM data analys is}

Comparisons of the sHVEM values of each patient and the healthy controls were assessed by one-way ANOVA. The statistical analyses were performed with the Microcal ${ }^{\mathrm{TM}}$ Orijin ${ }^{\mathrm{TM}}$ software package (MicrocalSoftware, Inc, Northampton, MA). A P-value of less than 0.05 was considered statistically significant.

\section{Results}

\section{Anti-H VEM monoclonal antibodies}

To produce mAbs that recognize HVEM, the HVEMFc fusion protein was used for ELISA screening since the HVEM-GST fusion protein had been used as immunogen. Specificity was confirmed by lack of cross-reaction with GST and other bacterial proteins. Flow cytometry was used to identify mAbs that stained native cell surface HVEM so that the mAbs could be used in future studies of the functions of HVEM in human immune system. Positive clones were subcloned at least twice by limiting dilution. The ELISA ImmunoPure Monoclonal Antibody Isotyping Kit showed that $m A b 122$ and 108 were $l G_{1}$ subclass antibodies and mAb 139 was an $\operatorname{lgG}_{2 a}$ subclass antibody.

\section{Specificity of anti-HVEM}

To determine the specificity of the anti-HVEM mAbs, the hybridoma cell culture supernatants were used to 
108

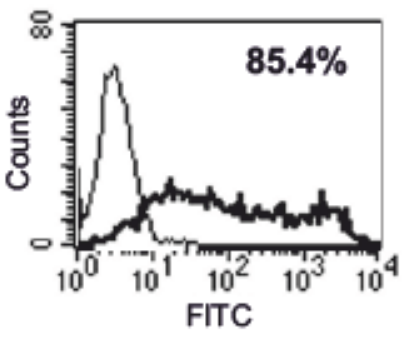

122

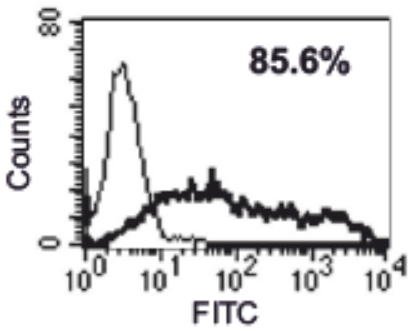

139

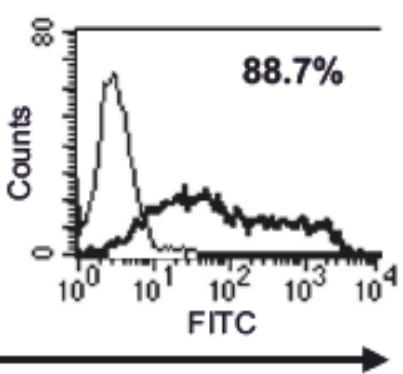

HVEM

Figure 1. Binding of mAbs to 293 cells transfected with HVEM PCDNA3. 293 cells, transiently transfected with sense (heavy lines) or antisense (hin lines) HVEM pCDNA3 for $48 \mathrm{~h}$, were incubated with hybridoma culture supematants followed by FITC-conjugated goat anti-mouse bG and subjected to cytometric analysis. All 3 mAbs, 122, 139, 108 recognized sense but not antsense transfectants.

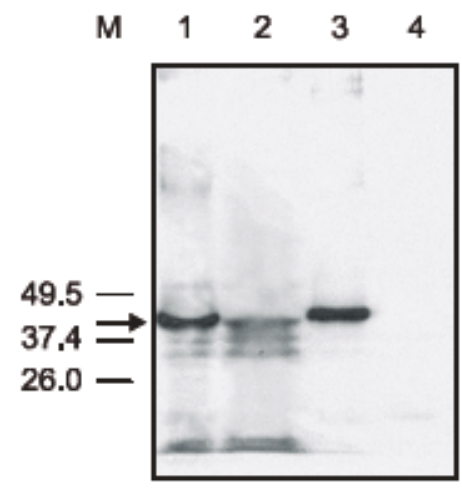

Figure 2. Westem blot analysis of HVEM. Cell lysates and HVEMGST samples were separated by SDS-PAGE, and analyzed by Weslem blotting with mAh108. Lane M; protein size markers, lane 1 , THP-1 cells; lane 2, Jurkat cells; lane 3, HVEM-GST (02 $\mu \mathrm{g}$ Well $)$; lane 4, GST. Arrow indicales HVEM. stain 293 cells transfected with either sense or antisense HVEM cDNA. Goat anti-mouse-FITC conjugated antibody was used as secondary antibody. Flow cytometric analysis showed that all three selected mAbs recognized sense but not anti-sense HVEM. This indicates that all three mAbs are specific for surface expressed HVEM (Figure 1). The slight difference between the three mAbs in staining efficiency may result from: 1) different binding affinities, 2) recognition of different HVEM epitopes, or 3) different concentrations in the culture supematants. Anti-HVEM mAbs 122 , 108 and 139 recognized different epitopes on HVEM since they did not compete for $\mathrm{Ag}$ (data not shown), and therefore were used in ELISAs for SHVEM.

The specificity of the mAbs was further analyzed by Western blot analyses with mAb 108 from cell

Resting
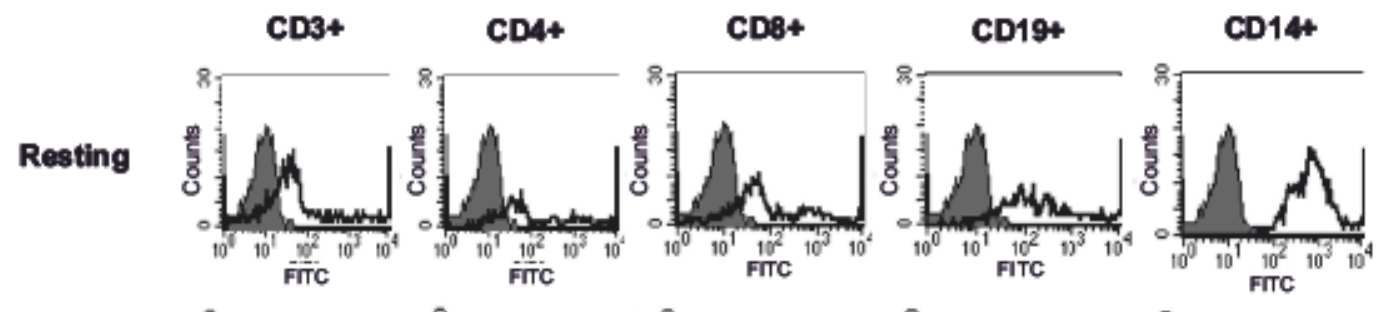

neutrophils
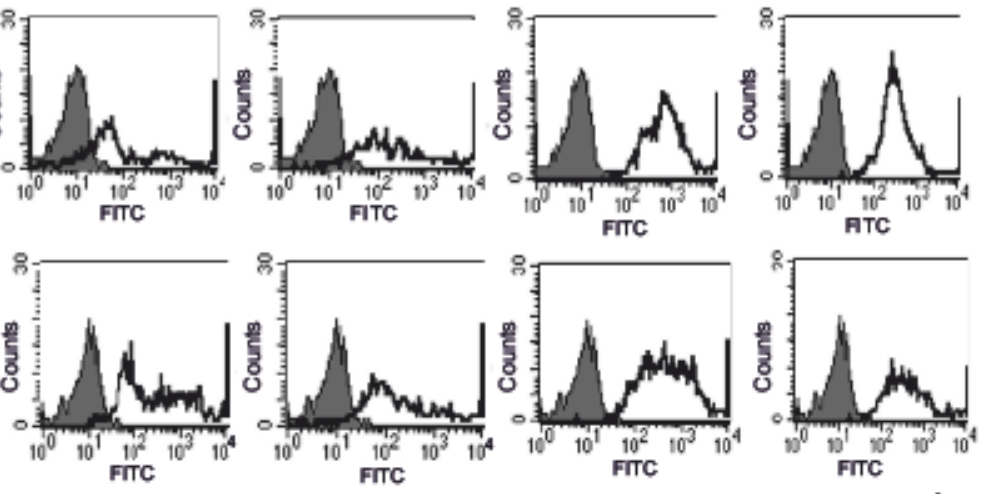

Activating
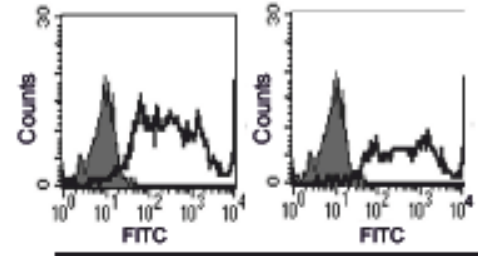

\section{HVEM}

Figure 3. HVEM expression and distibufon on human peripheral blood mononuclear cells detected with mAb 122. Human PBMC were isolated from healthy adult volunileers as described in Materials and Methods, and incubated with mlgG1 (filled peaks) or mAb 122 (clear peaks), followed by FIC-conjugated goat anti-mouse $\mathrm{gG}$. In addition, the PBMC were subjected to a second color fluorescence with Tric-conjugaled anti-CD4, CD8, CD14 or CD19 mAbs. Analysis was performed with a FACscan. 
lysates and HVEM-GST to detect protein fragments (Figure 2). Lysates from intact cells showed a major band at $40.0 \mathrm{kDa}$ with some smaller fragments between 32.0 and $39.0 \mathrm{kDa}$ (Figure 2, lane 1 and 2). HVEMGST gave a single band of $42.2 \mathrm{kDa}$ recognized by the anti-HVEM (Figure 2, lane 3). Thus, it is likely that natural form of HVEM is $40.0 \mathrm{kDa}$ glycoprotein.

\section{HVEM expression}

Immunostaining with $\mathrm{mAb} 122\left(\mathrm{mlg}_{1}\right)$ yielded generally the highest intensity of staining and the lowest non-specific background. Flow cytometric analysis of human PBMC using two color analysis, showed that HVEM was constitutively expressed on $\mathrm{CD}^{*} \mathrm{~T}$ lymphocytes, including both $\mathrm{CD4^{* }}$ and $\mathrm{CD} 8^{*}$ subsets, and was also highly expressed on $\mathrm{CD}^{\circ} 9^{*} \mathrm{~B}$ lymphocytes, $\mathrm{CD} 14^{*}$ monocytes and neutrophils (Figure 3 ). Expression on T cells increased marginally after $24 \mathrm{~h}$ stimulation. As previously shown [5], freshly isolated peripheral $T$ cells expressed high levels of HVEM. When cells were activated for 3 days, expression decreased slightly (data not shown). HVEM may be constitutively expressed in $\mathrm{T}$ cells in the absence of stimulation.

The expression pattern of HVEM was investigated on myeloid cells such as dendritic cells (DCs). HVEM was constitutively expressed at a high level on peripheral monocyte-derived immature DCs (Figure 4). Expression barely changed after maturation with an inflammatory cytokine such as TNF- $\alpha$ (Figure 4A). Expression was also detected on $\mathrm{CD} 34^{*} \mathrm{DCs}$ derived from cord blood cells (Figure 4B), but activation of these mature DCs with LPS had little effect on expression (data not shown).

\section{Effect of anti-HVEM mAbs on MLR proliferation responses}

In order to examine the stimulatory or inhibitory capacity of the mAbs, their effect on a three-way mixed leukocyte reaction (MLR) were tested. As shown in Figure 5, mAb 122 strongly enhanced PBMC proliferation; mAb 139 also had a stimulatory effect, whereas mAb 108 blocked the MLR-mediated PBMC proliferation. We conclude that 122 and 139 are agonistic $\mathrm{mAbs}$, and 108 is an antagonistic $\mathrm{mAb}$.

\section{sHVEM in human serum}

Apart from some decoy receptors, molecules of the TNF receptor superfamily are cell surface molecules. However, they can be cleaved from the cell membrane in some clinical situations, generating soluble derivatives. We investigated SHVEM levels in sera from healthy donors, and patients with certain immunological diseases (atopic dermatitis; AD, psoriasis;
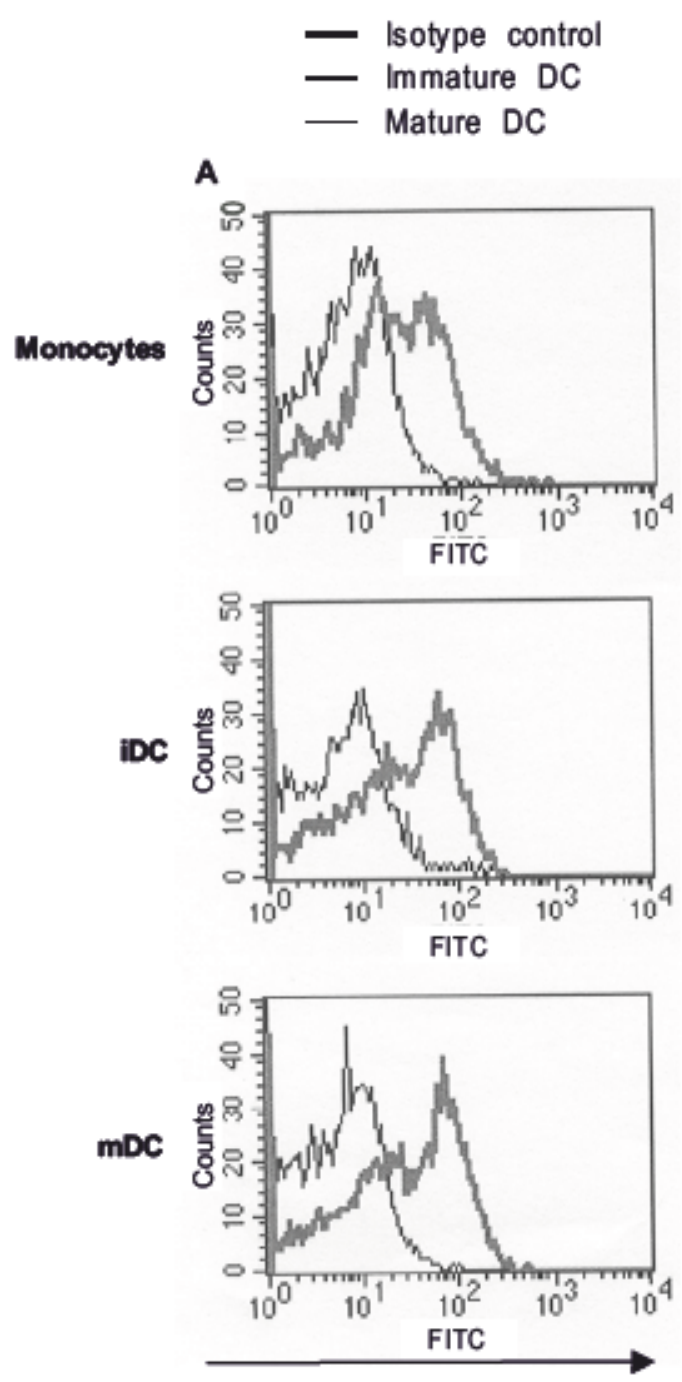

HVEM

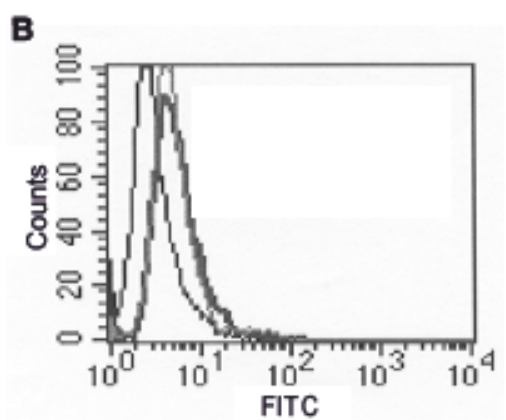

Figure 4. HVEM expression on monocytes, IDC and mDC. DC were prepared from PBMC (A), or from cord blood CD34 cells (B) as described in Materials and Mehods. IDC were harvested on day 5 of culture and incubaled for an additional 2 days with TNF- $\alpha$, b produce MDC. DC were stained with anti-CD11C-PE and anti-HVEMFITC and analyzed by fow cytomety. HVEM was delected by mAb122 (heavy lines or by control IgG, (light line) in (A). Shigted heavy (mature DC) and light (immature DC) lines indicate HVEM expression. 


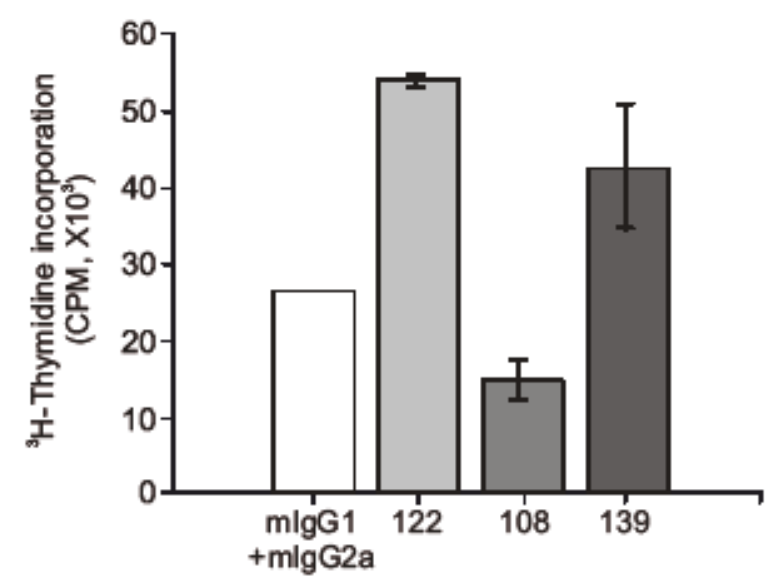

Monoclonal antibody

Figure 5. Effect of mAbs on a mixed leukocyle reaction (MLR). PBMC from two donors were adjusted to $1 \times 10^{8}$ cells $/ \mathrm{mL}$. Fifty microliters of each cell suspension was added in quadruplicale to 96 -well round bottom plates, together with $4 \mu \mathrm{g} /$ well of anti-HVEM mAb or control mAbs. Tobl volume of each well was adjusted to $200 \mu$ liwell. The plate was incubated for 3 days and ${ }^{3} \mathrm{H}$ )thymidine was added to each well for an additional $12 \mathrm{~h}$. The hree anti-HVEM mAbs $122\left(\mathrm{lgG}_{1}\right)$, $108\left(\mathrm{lg}_{1}\right)$ and $139\left(\mathrm{lgG}_{2 \mathrm{a}}\right)$ were used. $\mathrm{mlg}_{1}$ and $m \mathrm{mg}_{2 \mathrm{a}}$ are $\mathrm{lg}$ isolype controls. [ $\left.^{3} \mathrm{H}\right)$ thymidine incorporation was measured as an indicafion of proliferation. Values are mean $\pm S D$.

PSO, allergic asthma; AA, rheumatoid arthritis; RA, systemic lupus erythematosus; SLE, Bechet's disease; $B D$ ) and with pneumonia ( $P$ ) and lung cancer (LC) using a sandwich ELISA technique (Figure 6).

sHVEM was significantly elevated in sera of patients with $A D$ (mean $\pm S D ; 718 \pm 617 \mathrm{pg} / \mathrm{ml} ; P<$ $0.01)$, with $\mathrm{AA}(871 \pm 712 \mathrm{pg} / \mathrm{ml} ; P<0.001)$, with $\mathrm{RA}$ $(1638 \pm 1366 \mathrm{pg} / \mathrm{ml} ; P<0.001)$, with SLE $(544 \pm 395$ $\mathrm{pg} / \mathrm{ml} ; P<0.05)$, with BD $(755 \pm 790 \mathrm{pg} / \mathrm{ml} ; P<0.05)$, and with pneumonia $(808 \pm 557 \mathrm{pg} / \mathrm{ml} ; \quad P<0.05)$ compared with those of healthy controls $(304 \pm 184$ $\mathrm{pg} / \mathrm{ml}$ ). Sera from patients with LC had very low levels $(100 \pm 57 \mathrm{pg} / \mathrm{ml})$ of sHVEM. Thus our data indicate that significantly higher levels of SHVEM are present in sera of patients with immunological disorders such as $A A$, and RA than in healthy control. Although $A D$ and SLE show a trend of high serum concentration of sHVEM, a conclusion can not be drawn because of small sample size.

\section{Discussion}

Earlier study showed that HVEM expression at the mRNA level was most prominent in lymphoid tissues such as thymus, spleen and peripheral blood leukocytes (PBLs), although it had a wide tissue distribution; HVEM mRNA was also abundant in both resting and activated $\mathrm{CD}^{*}$ and $\mathrm{CD}^{*} \mathrm{~T}$ cells, $\mathrm{CD}^{*}{ }^{*} \mathrm{~B}$ cells,

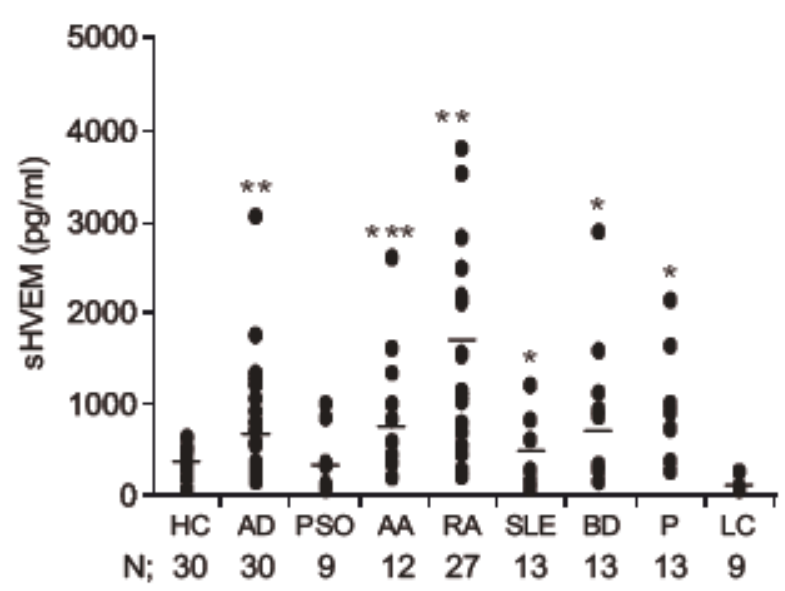

Figure 6. Soluble HVEM (sHVEM) levels in sera of patients and healthy donors determined by ELISA. The data are means of tiplicales, and horizontal bars depict means. "*t $p<0.001$, ${ }^{* *} p<0.01$, and ${ }^{*} P<0.05$ compared with the control group. $\mathrm{HC}$, healhy controls; $A D$, abpic dermatifs; PSO, psoriasis; $A A$, allergic asthma; RA, meumatoid arthrits; SLE, syslemic lupus erythematosus; BD, Bechets disease; $\mathbf{P}$, pneumonia; LC, lung cancer, and $\mathbf{N}$, number of donors in each group.

and monocytes (Kwon et al., 1997). Consistent with those results, present study confirmed that there is cell surface expression of HVEM on primary T cells, $B$ cells and monocytes. In addition, HVEM was detected on other immune cells such as neutrophils, monocytes and $\mathrm{CD} 34^{*}$ cord blood cell-derived DCs. This indicates that HVEM is widely expressed on immune cells and is not restricted to any subpopulations of PBLs. This wide distribution seems to be unique to HVEM, since expression of most TNF receptor superfamily members is restricted to particular immune cells (Gruss, 1996; Lotz et al., 1996). The expression pattern of HVEM suggests that it may play a role in multiple aspects of the immune response. Since the expression of LIGHT (the HVEM ligand) on $T$ cells is induced after activation, $T$ cell activation through HVEM signaling may involve interaction of $\mathrm{T}$ cells with each other. Indeed, blockade of HVEM-LIGHT interactions inhibits proliferation of highly purified T cells in response to TCR stimulation (Shaikh et al., 2001). Thus, co-stimulation via HVEM depends on the presence of LIGHT on T cells (Morel et al., 2000; Scheu et al., 2002). Interestingly, Morel et al. (2002) have provided evidence that HVEM expression is down-regulated by stimulation of LIGHT on activated T cells, suggesting that the HVEM-LIGHT system is self-regulating (Morel et al., 2002). In sum, co-stimulation of T cells via HVEM signaling is likely to be reinforced by LIGHT expression following TCR engagement, and turned off after down-regulation of cell surface HVEM by LIGHT.

At present, it is not known what function HVEM 
has on B cells. Data presented here, and elsewhere, show that B cells express high levels of HVEM, suggesting that it may be involved in $\mathrm{B}$ cell function (Harrop et al., 1998). Since LIGHT is expressed on activated $T$ cells, and transgenic mice that express LIGHT in their T cell lineage produce elevated levels of auto-antibodies (showing a systemic lupus erythematosus phenotype), HVEM signaling on B cells may play a role in antibody production (Wang et al., 2001). The HVEM-LIGHT system could influence antibody production in two ways. First, the engagement of HVEM by LIGHT on activated T cells might enhance $B$ cell activities. Second, stimulation of DC HVEM by LIGHT on activated T cells might activate DCs such that they in turn enhance B cell functions.

The expression and distribution of HVEM on various established cell lines varied according to the proportion of cells used and their state of activation. It was constitutively expressed on the monocyte-like cell lines THP-1 and U937, whereas only very low levels were found on HL-60, human $C D 4^{*} \mathrm{~T}$ cells, Jurkat cells, PM-1, and the B-cell line Frev. Expression on HL-60, THP-1, U937, and Jurkat cells was significantly increased after 3 days stimulation with PMA (unpublished observation). Expression pattern of HVEM protein was similar to the mRNA expression data previously published by our laboratories (Lee et al., 2001) but there were differences in expression level that might be due to: 1) posttranslational modification, 2) configuration and presentation of epitopes recognized by the mAbs, 3) $\mathrm{mAb}$ sensitivity.

The effect of the anti-HVEM monoclonal antibodies was examined in a mixed lymphocyte reaction (MLR). As shown in Figure 5, mAb 122 was stimulatory and mAb 108 inhibitory. MAb 139 was also stimulatory although less than mAb 122. These data can be interpreted as that HVEM and HVEM ligand are involved in cell-cell interaction in the MRL reaction and that an anti-HVEM $\mathrm{mAb}$ can behave in two different ways: MAb 122 and mAb 139 may be signaling mAbs that can activate lymphocytes by crosslinking HVEM, whereas mAb 108 is a blocking $\mathrm{mAb}$ which binds to HVEM but does not generate a signal. These monoclonal antibodies will be useful in determining the role of HVEM in T cell co-stimulation.

Processes mediated by members of the TNF receptor superfamily can be modified by proteolytic cleavage and shedding of cell surface TNF receptors. It is thought that soluble TNF receptors can compete with surface forms of the receptors, thereby decreasing the efficacy of their ligands (Salih et al., 2001). This may affect cell-cell interactions and responses to receptor ligands, or it may provoke more distal responses to cellular activation (McGeehan et al., 1994). This study showed that considerable amounts of soluble HVEM exist in sera of patients with certain diseases, and that it is significantly elevated in patients with allergic diseases (atopic dermatitis and allergic asthma), autoimmune disease (rheumatoid arthritis), and inflammatory disease (pneumonia). According to previous reports (Cheng et al., 1994; Michel et al., 1998; Schneider et al., 1998), there are high levels of soluble (s) Fas (sFas) and s4-1BB in sera of patients with multiple sclerosis and rheumatoid arthritis. The functions of SHVEM are not known but the present study suggests a more specific role in certain diseases. It will be important to determine whether the level of sHVEM in patient serum is correlated with progress and outcome of the disease (Sharief, 2002).

In sum, this study demonstrated HVEM expression in a variety of immune cells, including $T$ cells, B cells, monocytes, neutrophils and DCs. Like other members of the TNF receptor superfamily, soluble HVEM exists in sera of patients with immunological disorders. The levels of sHVEM in the serum of lung cancer patients were even lower than that in the serum of normal controls. Lung cancer samples were employed as a disease control in this study. We therefore do not know whether the low serum level of SHVEM in lung cancer patients reflects any immunological significance or immune competency of the patients. It certainly warrants further studies.

\section{Acknowlegement}

This work was supported by the Korean Research Foundation (KRF2001-015-DP0553), and SRC fund to UOU from KOSEF and the Korean Ministry of Science and Technology, KKK was supported by Basic Research Program of KOSEF (NO. 2000-1-20500-001-5).

\section{References}

Brown JA, Dorfman DM, Ma FR, Sullivan EL, Munoz O, Wood CR, Greenfield EA, Freeman GJ. Blocade of programmed death-1 ligands on dendritic cells enhances $T$ cell activation and cytokine production. J Immunol 2003;170: $1257-66$

Cheng J, Zhou T, Liu C, Shapiro JP. Protection from Fasmediated apoptosis by a soluble form of the sFas molecule. Science 1994;263:1759-62

Coligan JE, Kruisboek AM, Margulies DH, Shevach EM, Strober W. Current protocols in immunology, 1991, WileyInterscience, New York

Gruss HJ. Molecular, structural, and biological characteristics of the tumor necrosis factor ligand superfamily Review. Int J Clin \& Lab Resc 1996;26:143-59

Harrop JA, Reddy M, Dede $K$, Brigham-Burke $M$, Lyn S, Tan $K B$, Silverman C, Eichman C, DiPrinzio R, Spampanato J, Porter T, Holmes S, Young PR, Truneh A. Antibodies b TR2 
(herpes virus entry mediator), a new member of the TNF superfamily, block $T$ cell proliferation, expression of activation markers, and production of cytokines. J Immunol 1998; 161:1786-94

Hsu H, Solovyev I, Colombero A, Elliott R, Kelley M, Boyle WJ. ATAR, a novel tumor necrosis factor receptor family member, signals through TRAF2 and TRAF5. J Biol Chem $1997 ; 272: 13471-4$

Kohler G, Milstein C. Continuous cultures of fused cells secreting antibody of predefined specificity. Nature $1975 ; 256$ : 495-497

Kwon B, Kim BS, Cho HR, Park JE, Kwon BS. Involvement of tumor necrosis factor receptor superfamily (TNFRSF) members in the pathogenesis of inflammatory disease. Exp Mol Med 2003;1:8-16

Kwon BS, Tan KB, Ni J, Oh KO, Lee ZH, Kim KK, Kim YJ, Wang S, Gentz R, Yu GL, Harrop J, Lyn SD, Silverman C, Poster TG, Truneh A, Young PR. A newly-identified member of the tumor necrosis factor receptor superfamily with a wide tissue distribution and involvement in lymphocyte activation. J Biol Chem 1997;272:14272-6

Jin $Y$, Kim KY, Soung NK, Shin EY, Kim EG, Kim SR. Production and characterization of monoclonal antibodies against amphiphysins. Exp Mol Med 2001;2:69-75.

Lee WH, Kim SH, Lee BB, Kwon B, Song H, Kwon BS, Park JE. TNFRSF14 is involved in atherogenesis by inducing pro-inflammatory cytokines and matrix metalloproteinases. Arterioscler Thromb Vasc Biol 2001;2:2004-10

Locksley RM, Killeen N, Lenardo MJ. The TNF and TNF receptor superfamilies: integrating mammalian biology. Cell 2001;104:487-501

Lotz $M$, Setareh $M$, von Kempis J, Schwarz $H$. The nerve growth factor/tumor necrosis factor receptor family [Review]. J Leukocyte Bio $1996 ; 60: 1-7$

Mallett S, Barclay AN. A new superfamily of cell surface proteins related to the nevve growth factor receptor. Immunol Today 7 1991;220-3

Montgomery RI, Warner MS, Lum B, Spear PG. Herpes simplex virus 1 entry into cells mediated by a novel member of the TNF-NGF receptor family. Cell 1996;87:427-36

Marsters SA, Ayres TM, Skubatch M, Gray CL, Rothe M, Ashkenazi A. Herpes virus entry mediator, a member of the tumor necrosis factor receptor (TNFR) family, interacts with members of the TNFR-associated factor family and activates the transcription factor NF- $\mathrm{KB}$ and Ap-1.J Biol Chem 1997; 272:14029-32

McGeehan GM, Becherer JD, Bast RC, Boyer Jr., CM, Champion B, Connolly KM, Conway JG, Furdon P, Karp $S$, Kidao S. Regulation of tumor necrosis factor- $\alpha$ processing by a metalloproteinase inhibitor. Nature 1994;370:558-63

Michel J, Langstein J, Hofstadter F, Schwarz H. A soluble form of CD137 (ILAV4-1BB) is released by activated lymphocytes and is detectable in sera of patients with ineumatoid arthritis. Eur J Immunol 1998;28:290-5

Morel Y, Schiano de Colella JM, Harrop J, Deen KC, Holmes SD, Wattam TA, Khandekar SS, Truneh A, Sweet RW, Gastaut JA, Olive D, Costello RT. Reciprocal expression of the TNF family receptor herpes virus entry mediator and its ligand LIGHT on activated T cells: LIGHT down-regulates its own receptor. J Immunol 2000;165:4397-404

Morel Y, Schiano de Colella JM, Harrop J, Deen KC, Holmes SD, Wattam TA, Khandekar SS, Truneh A, Sweet RW, Gastaut JA, Olive D, Costello RT. Cutting edge: Selective impairment of CD8+ T cell function in mice lacking the TNF superfamily member LIGHT. J Immunol 2002;168:4832-5

Salih HR, Schmetzer HM, Burke C, Starling GC, Dunn R, Pelka-Fleischer R, Nuessler V, Kiener PA. Soluble CD137 (4-1BB) ligand is released following leukocyte activation and is found in sera of patients with hematological malignancies. $\mathrm{J}$ Immunol 2001;167:4059-66

Scheu S, Alferink J, Potzel T, Barchet W, Kalinke U, Pfeffer K. Targeted distruption of LIGHT caises detects in costimulatory $\mathrm{T}$ cell activation and reveals cooperation with lymphtoxin $\beta$ in mesenteric lymph node genesis. J Exp Med 2002;195:1613-24

Schneider $P$, Holler $N$, Bodmer JL, Hahne M, Frei $K$, Fontana A, Tschopp J. Conversion of membrane-bound Fas (CD95) ligand to its soluble form is associated with downregulation of the proapoptotic activity and loss its liver activity. J Exp Med 1998;187:1205-11

Shaikh RB, Santee S, Granger SW, Butrovich K, Cheung $T$, Kronenberg $M$, Cheroutre $H$, Ware CF. Constitutive expression of LIGHT on T cells leads to lymphocyte activation, inflammation, and tissue destruction. J Immunol 2001; $167: 6330-7$

Sharief MK., Hightened intrathecal release of soluble CD 137 in patients with mulfiple sclerosis. Eur J Neurol 2002;9:49-54

Wang J, Lo JC, Foster A, Yu P, Chen HM, Wang Y, Tamada $\mathrm{K}$, Chen $\mathrm{L}, \mathrm{Fu} \mathrm{YX}$. The regulation of $\mathrm{T}$ cell homeostasis and autoimmunity by $\mathrm{T}$ cell-derived LIGHT. J Clin Invest 2001; 108:1771-80

Whitheck JC, Peng C, Lou H, Xu R, Willis SH, Ponce de Leon $M$, Peng T, Nicola AV, Montgomery RI, Warner MS, Soulika AM, Spruce LA, Moore WT, Lambris JD, Spear PG Cohen GH, Eisenberg RJ. Glycoprotein D of herpes simplex virus (HSV) binds directly to HVEM, a member of the tumor necrosis factor receptor superfamily and a mediator of HSV entry. J Virol 1997;71:6083-94 